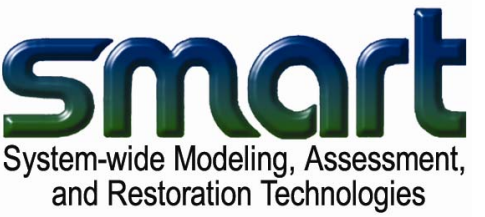

\title{
Watershed Analysis with the Hydrologic Engineering Center's River Analysis System (HEC-RAS)
}

\author{
by Christopher R. Goodell and Gary W. Brunner
}

PURPOSE: The objectives of this document are to provide a general description of the HECRAS model, its capabilities and limitations, data requirements, traditional and innovative methods for HEC-RAS hydraulic model calibration, and to present a case study HEC-RAS model application whereby the capabilities of HEC-RAS are demonstrated as a means to support system-wide modeling and assessment in a usable decision-support framework.

\section{MODEL DESCRIPTION}

Overview. HEC-RAS is an integrated system of software, designed for interactive use in a multi-tasking environment. The system is comprised of a graphical user interface (GUI), separate hydraulic analysis components, data storage and management capabilities, graphics and reporting facilities.

The HEC-RAS system will ultimately contain three one-dimensional hydraulic analysis components for: (1) steady flow water surface profile computations; (2) unsteady flow simulation; and (3) movable boundary sediment transport computations. A key element is that all three components will use a common geometric data representation and common geometric and hydraulic computation routines. In addition to the three hydraulic analysis components, the system contains several hydraulic design features that can be invoked once the basic water surface profiles are computed.

The current version of HEC-RAS supports steady and unsteady flow water surface profile calculations. New features and additional capabilities will be added in future releases. On-line help is available from within the HEC-RAS software. Help can be accessed by selecting the Help menu option at the top of each window, or by pressing the F1 function key.

Capabilities and Limitations. HEC-RAS is designed to perform one-dimensional hydraulic calculations for a full network of natural and constructed channels. The following is a description of the major capabilities of HEC-RAS.

The user interacts with HEC-RAS through a graphical user interface (GUI). The main focus in the design of the interface was to make it easy to use the software, while still maintaining a high level of efficiency for the user. The interface provides for the following functions:

- File management.

- Data entry and editing.

- Hydraulic analyses.

- Tabulation and graphical displays of input and output data. 
- Reporting facilities.

- On-line help.

Steady flow water surface profiles. The Steady Flow Water Surface Profiles component of the modeling system is intended for calculating water surface profiles for steady gradually varied flow. The system can handle a full network of channels, a dendritic system, or a single river reach. The steady flow component is capable of modeling subcritical, supercritical, and mixed flow regime water surface profiles.

The basic computational procedure is based on the solution of the one-dimensional energy equation. Energy losses are evaluated by friction (Manning's equation) and contraction/ expansion (coefficient multiplied by the change in velocity head). The momentum equation is utilized in situations where the water surface profile is rapidly varied. These situations include mixed flow regime calculations (i.e., hydraulic jumps), hydraulics of bridges, and evaluating profiles at river confluences (stream junctions).

The effects of various obstructions such as bridges, culverts, weirs, and structures in the flood plain may be considered in the computations. The steady flow system is designed for application in flood plain management and flood insurance studies to evaluate floodway encroachments. Also, capabilities are available for assessing the change in water surface profiles due to channel improvements, and levees.

Unsteady flow simulation. This component of the HEC-RAS modeling system is capable of simulating one-dimensional unsteady flow through a full network of open channels. The unsteady flow equation solver was adapted from Dr. Robert L. Barkau's UNET model (Barkau 1992, HEC 1997). This unsteady flow component was developed primarily for subcritical flow regime calculations. However, with the release of Version 3.1, the model can now perform mixed flow regime (subcritical, supercritical, hydraulic jumps, and drawdowns) calculations in the unsteady flow computations module. The hydraulic calculations for cross sections, bridges, culverts, and other hydraulic structures that were developed for the steady flow component were incorporated into the unsteady flow module.

Sediment transport/movable boundary computations. This component of the modeling system is intended for the simulation of one-dimensional sediment transport/movable boundary calculations resulting from scour and deposition over moderate time periods (typically years, although applications to single flood events are possible).

The sediment transport potential is computed by grain size fraction, thereby allowing the simulation of hydraulic sorting and armoring. Major features will include the ability to model a full network of streams, channel dredging, various levee and encroachment alternatives, and the use of several different equations for the computation of sediment transport.

The model will be designed to simulate long-term trends of scour and deposition in a stream channel that might result from modifying the frequency and duration of the water discharge and stage, or modifying the channel geometry. This system can be used to evaluate deposition in reservoirs, design channel contractions required to maintain navigation depths, predict the 
influence of dredging on the rate of deposition, estimate maximum possible scour during large flood events, and evaluate sedimentation in fixed channels.

Data storage and management. Data storage is accomplished through the use of "flat" files (ASCII and binary), as well as the HEC-DSS (Data Storage System). User input data are stored in flat files under separate categories of project, plan, geometry, steady flow, unsteady flow, and sediment data. Output data are predominantly stored in separate binary files. Data can be transferred between HEC-RAS and other programs by utilizing the HEC-DSS.

Data management is accomplished through the user interface. The modeler is requested to enter a single file name for the project being developed. Once the project file name is entered, all other files are automatically created and named by the interface as needed. The interface provides for renaming, moving, and deleting files on a project-by-project basis.

Graphics and reporting. Graphics include X-Y plots of the river system schematic, cross sections, profiles, rating curves, hydrographs, and many other hydraulic variables. A threedimensional plot of multiple cross sections is also provided. Tabular output is available. Users can select from pre-defined tables or develop their own customized tables. All graphical and tabular output can be displayed on the screen, sent directly to a printer (or plotter), or passed through the Windows Clipboard to other software, such as a word processor or spreadsheet. Reporting facilities allow for printed output of input data as well as output data. Reports can be customized as to the amount and type of information desired.

History. The HEC-RAS modeling system was developed as a part of HEC's "Next Generation" (NexGen) of hydrologic engineering software. The NexGen project encompasses several aspects of hydrologic engineering, including: rainfall-runoff analysis; river hydraulics; reservoir system simulation; flood damage analysis; and real-time river forecasting for reservoir operations.

The first version of HEC-RAS (Version 1.0) was released in July of 1995. Since that time, there have been several releases of this software package, including Versions: $1.1 ; 1.2 ; 2.0 ; 2.1 ; 2.2$; $2.21 ; 3.0 ; 3.1$; and 3.1.1. Version 3.0 was the first version to include unsteady flow computations. Version 3.1 included the first look at sediment transport, with the introduction of sediment transport capacity and stable channel design functions. Future versions of HEC-RAS will have the HEC-6 style sediment transport capabilities, such as temporal analysis of system-wide scour and deposition.

General Description. HEC-RAS is an integrated package of hydraulic analysis programs in which the user interacts with the system through the use of a graphical user interface (GUI). The system is capable of performing steady and unsteady flow water surface profile calculations, and will include sediment transport and several hydraulic design computations in the future.

In HEC-RAS terminology, a project is a set of data files associated with a particular river system. The modeler can perform any or all of the various types of analyses included in the HEC-RAS package as part of the project. The data files for a project are categorized as follows: plan data, geometric data, steady flow data, unsteady flow data, sediment data, and hydraulic design data. 
During the course of a study, the modeler may want to formulate several different plans. Each plan represents a specific set of geometric data and flow data. Once the basic data are entered into the HEC-RAS, the modeler can easily formulate new plans. After simulations are made for the various plans, the results can be compared simultaneously in both tabular and graphical form.

HEC-RAS starts with the main window shown in Figure 1.

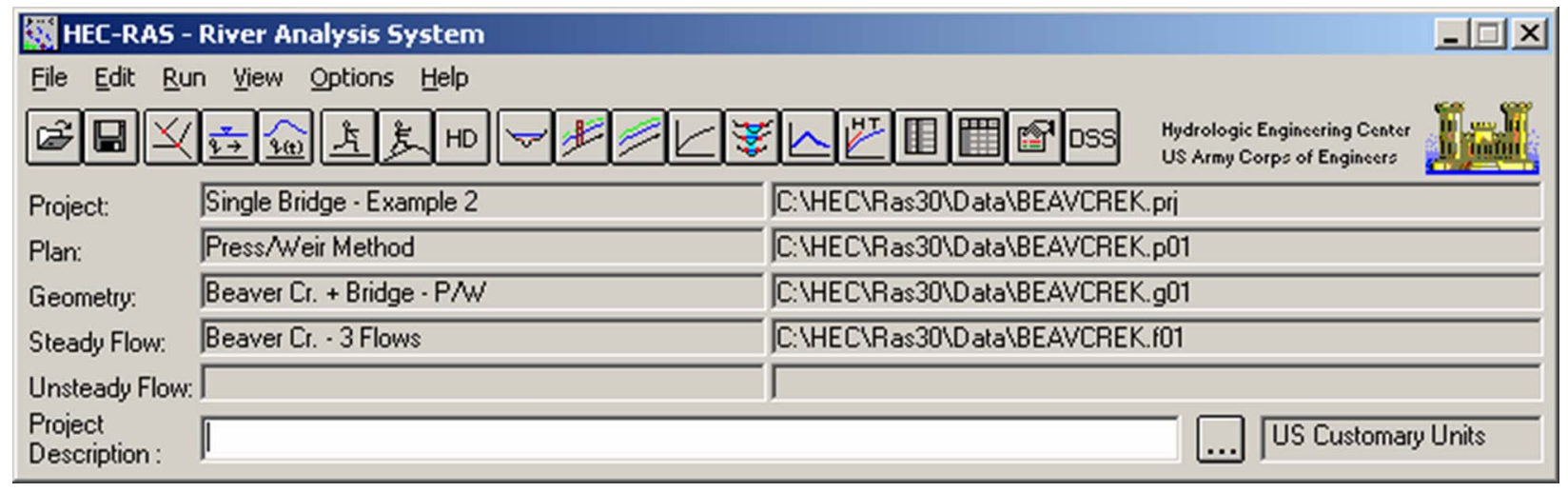

Figure 1. HEC-RAS main window

Entering geometric data. The next step is to enter the necessary geometric data, which consist of connectivity information for the stream system (river system schematic), cross-section data, and hydraulic structure data (bridges, culverts, weirs, etc.). See Figure 2.

After the river system schematic is developed, the modeler can start entering cross-section and hydraulic structure data. The cross section editor is shown in Figure 3. As shown, each cross section has a river name, reach name, river station, and a description. The river, reach, and river station identifiers are used to describe where the cross section is located in the river system. The "River Station" identifier does not have to be the actual river station (miles or kilometers) at which the cross section is located on the stream, but it does have to be a numeric value (e.g., 1.1, $2,3.5$, etc.). The numeric value is used to place cross sections in the appropriate order within a reach.

The basic data required for each cross section are shown on the cross section data editor in Figure 3. Additional cross section features are available under Options from the menu bar. These options include: adding, copying, renaming, and deleting cross sections; adjusting cross section elevations, stations, and n or k values; skew cross section; ineffective flow areas; levees; blocked obstructions; adding a lid to a cross section; adding ice cover; adding a rating curve; horizontal variation of $\mathrm{n}$ or $\mathrm{k}$ values; and vertical variation of $\mathrm{n}$ values.

The cross section data editor also has the ability to plot any cross section or reach profile. Edit features are available to cut, copy, paste, insert, and delete data from the Cross Section X-Y Coordinates grid. 


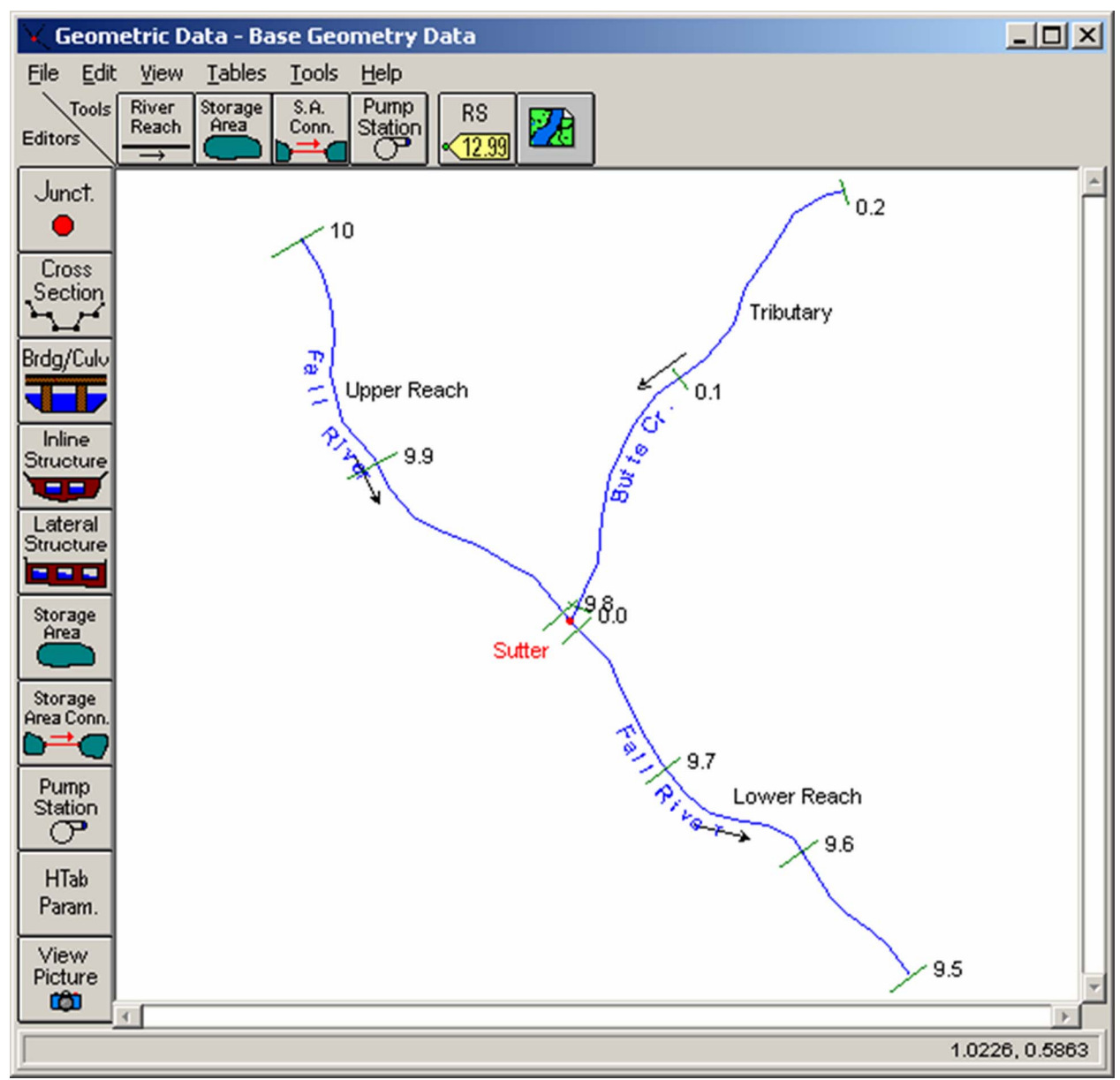

Figure 2. Geometric data plan view schematic

Once the cross-section data are entered, the modeler can then add hydraulic structures such as bridges, culverts, weirs, and spillways. Data editors, similar to the cross-section data editor, are available for the various types of hydraulic structures. If there are any stream junctions in the river system, additional data are required for each junction.

Entering flow data and boundary conditions. Figure 4 is an example of the steady flow data entry form, which is the steady flow data editor. As shown in Figure 4, steady flow data consist of: the number of profiles to be computed; the flow data; and the river system boundary conditions. Boundary conditions are required in order to perform the calculations. If a subcritical flow analysis is going to be performed, then only the downstream boundary conditions are required. If a supercritical flow analysis is going to be performed, then only the upstream boundary conditions are required. If the modeler is going to perform a mixed flow regime calculation, then both upstream and downstream boundary conditions are required. 
Cross Section Data - Base Geometry Data

Exit Édit Options Plot Help

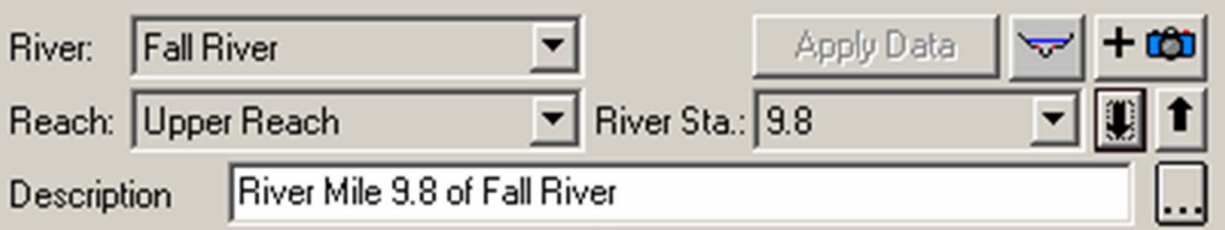

\begin{tabular}{|c|c|c|c|c|c|c|}
\hline \multicolumn{2}{|c|}{ Del Row } & \multicolumn{2}{|c|}{ Ins Row } & \multicolumn{3}{|c|}{ Downstream Reach Lengths } \\
\hline \multicolumn{4}{|c|}{ Cross Section $X-Y$ Coordinates } & LOB & Channel & $\mathrm{ROB}$ \\
\hline & Station & Elevation & $\Delta$ & 0 & 0 & 0 \\
\hline 1 & 110 & 89.1 & & \multicolumn{3}{|c|}{ Manning's n Values } \\
\hline 2 & 117.2 & 79.1 & & $\overline{\mathrm{LOB}}$ & \multirow{3}{*}{$\begin{array}{l}\text { Channel } \\
0.035\end{array}$} & ROB \\
\hline 3 & 174.8 & 77.1 & & 0.06 & & 0.05 \\
\hline 4 & 184.8 & 69.1 & & \multicolumn{2}{|c|}{ Main Channel Bank Stations } & \\
\hline 5 & 204.8 & 70.1 & & \multirow{2}{*}{ Left Bank } & & \multirow{2}{*}{ Right Bank } \\
\hline 6 & 214.8 & 78.1 & & & & \\
\hline 7 & 294 & 80.1 & & 174.8 & & 214.8 \\
\hline 8 & 301.2 & 90.1 & & \multicolumn{3}{|c|}{ Cont'Exp Coefficients } \\
\hline 9 & & & \multirow[b]{2}{*}{$\nabla$} & \multicolumn{2}{|c|}{ Contraction } & Expansion \\
\hline 10 & & & & 0.1 & 0.3 & \\
\hline
\end{tabular}

Enter to move to next downstream river station location

Figure 3. Cross section data editor

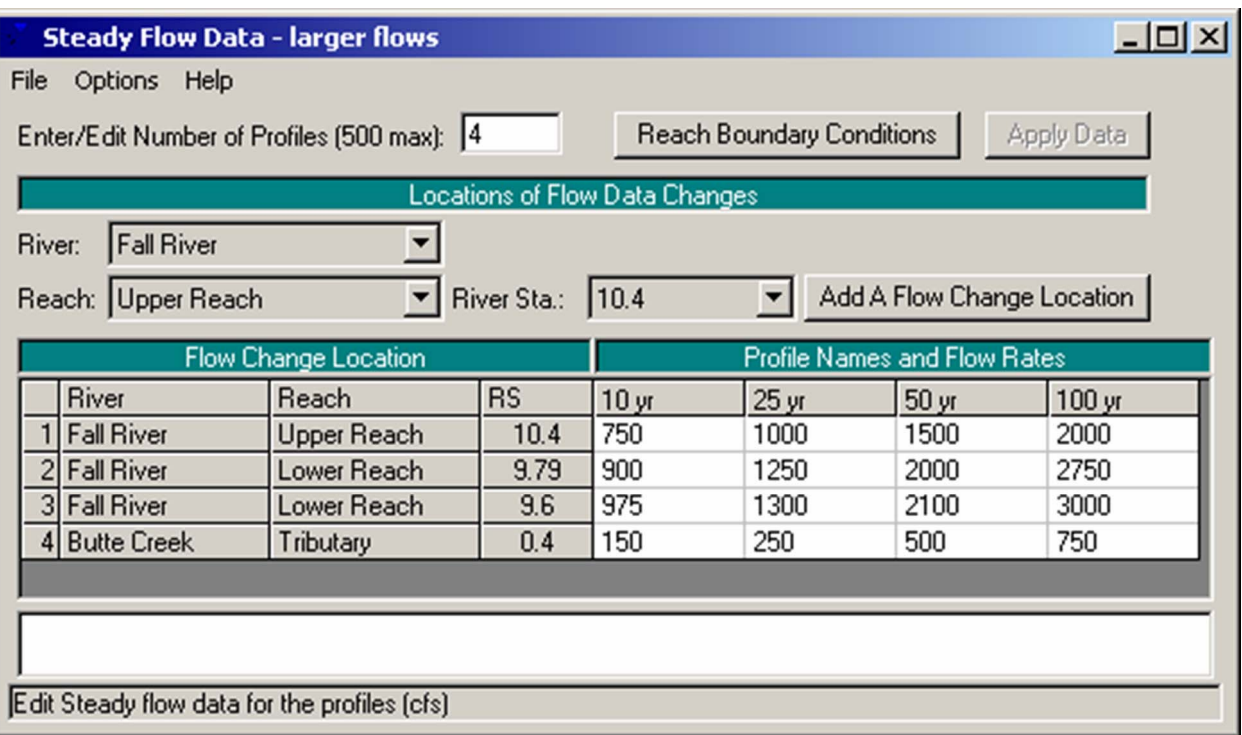

Figure 4. Steady flow data editor 
Performing the hydraulic computations. Once all of the geometric data and flow data are entered, the modeler can begin to perform the hydraulic calculations. As stated previously, there are three types of calculations that can be performed in the current version of HEC-RAS: Steady Flow Analysis, Unsteady Flow Analysis, and Hydraulic Design Functions. The modeler can select any of the available hydraulic analyses from the Run menu bar option on the HEC-RAS main window. An example of the Simulation Manager window is shown in Figure 5, which is the Steady Flow Analysis window. Subcritical, Supercritical, or Mixed flow regime calculations are available.

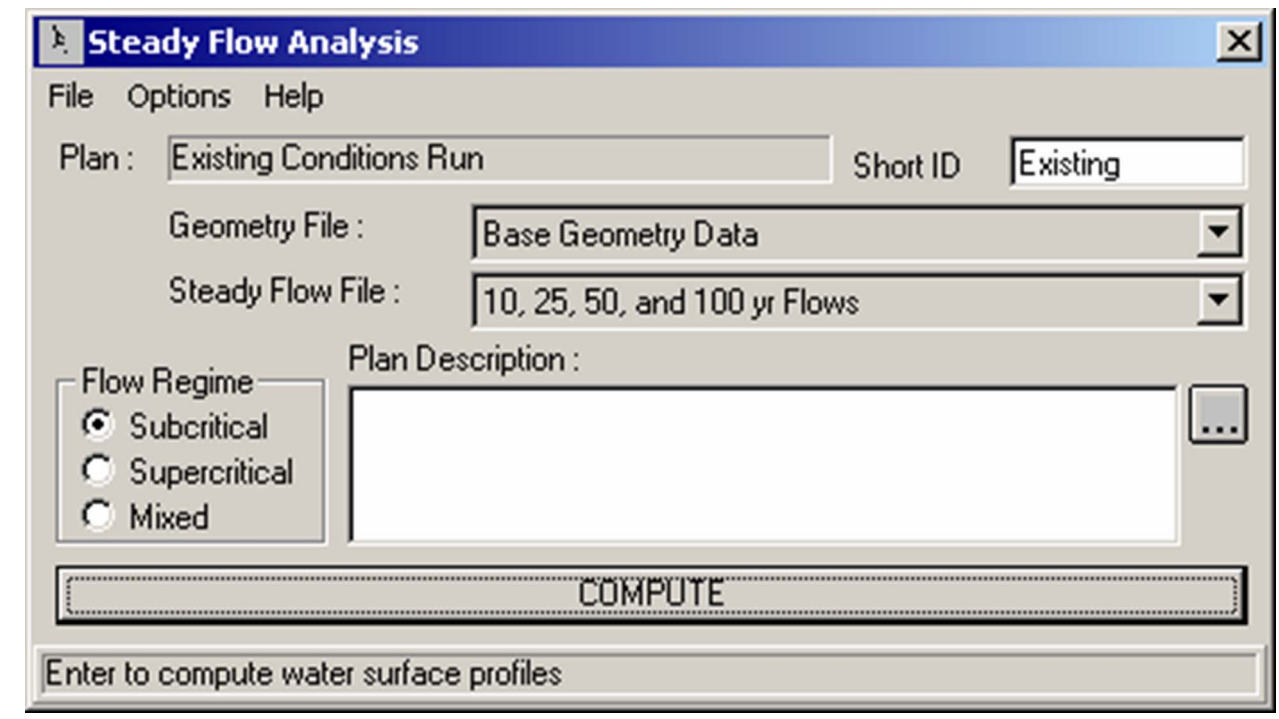

Figure 5. Steady Flow Analysis Window

Additional features are available under the Options menu for: performing a floodway encroachment analysis; setting locations for calculating flow distribution output; conveyance calculation options; friction slope methods; calculation tolerances; critical depth output; critical depth computation method; split flow optimization; data checking; setting log file levels; and viewing the log file output.

Once the modeler has selected a plan and set all of the calculation options, the steady flow calculations can be performed by pressing the compute button at the bottom of the steady flow analysis window. When this button is pressed, the HEC-RAS system packages up all the data for the selected plan and writes it to a run file. The system then runs the steady flow model (SNET) and passes it the name of the run file. This process is executed in a separate window. Therefore, the modeler can work on other tasks while it is executing.

Unsteady flow analysis. The user is required to enter boundary conditions at all of the external boundaries of the system, as well as any desired internal locations, and set the initial flow and storage area conditions at the beginning of the simulation.

Boundary conditions are entered by first selecting the "Boundary Conditions" tab from the Unsteady Flow Data editor, shown in Figure 6. River, Reach, and River Station locations of 


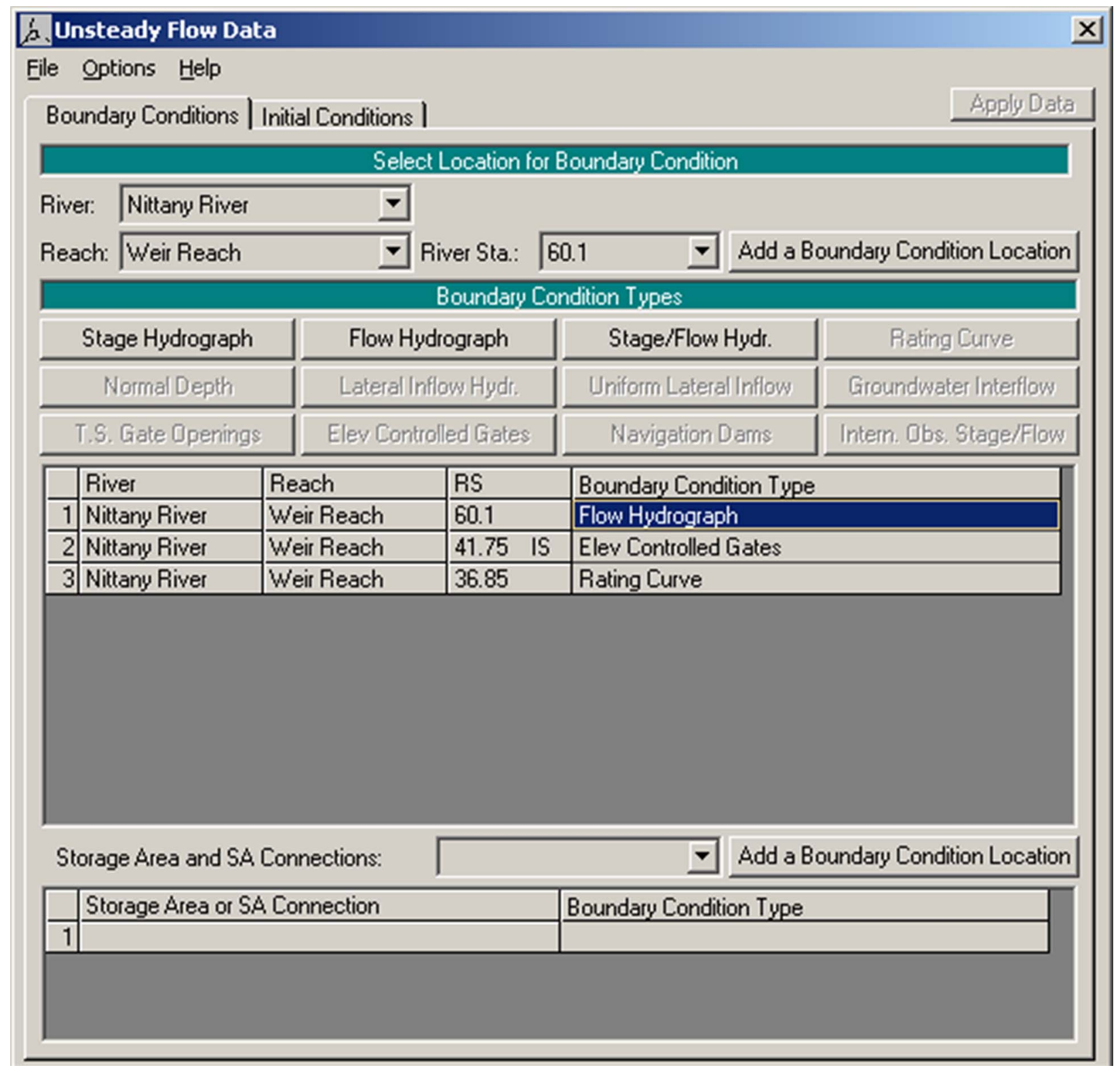

Figure 6. Unsteady flow data editor

the external bounds of the system will automatically be entered into the table. Boundary conditions are entered by first selecting a cell in the table for a particular location, then selecting the boundary condition type that is desired at that location. Not all boundary condition types are available for use at all locations. Users can also add locations for entering internal boundary conditions. Several different types of boundary conditions are available to the user. They are:

- Flow hydrograph.

- Stage hydrograph.

- Stage and flow hydrograph.

- Rating curve.

- Normal depth. 
- Lateral inflow hydrograph.

- Uniform lateral inflow hydrograph.

- Groundwater interflow.

- Time series of gate openings.

- Elevation controlled gate.

- Navigation dam.

- Internal observed stage and flow hydrograph.

In addition to the boundary conditions, the user must establish the initial conditions of the system at the beginning of the unsteady flow simulation. Initial conditions consist of flow and stage information at each of the cross sections, as well as elevations for any storage areas defined in the system. Initial conditions are established from within the unsteady flow data editor by selecting the "Initial Conditions" tab.

Three components are used in performing an unsteady flow analysis within HEC-RAS: a geometric data pre-processor; the unsteady flow simulator; and an output post-processor.

The pre-processor is used to process the geometric data into a series of hydraulic properties tables, rating curves, and family of rating curves, this speeds up the unsteady flow calculations. Instead of calculating hydraulic variables for each cross section, during each iteration, the program interpolates the hydraulic variables from the tables. The pre-processor must be executed at least once, but then only needs to be re-executed if something in the geometric data has changed. Cross sections are processed into tables of elevation versus hydraulic properties of areas, conveyances, and storage and hydraulic structures, such as bridges and culverts, are converted into families of rating curves that describe the structure as a function of tailwater, flow, and headwater.

The unsteady flow computations within HEC-RAS are performed by a modified version of the UNET (Unsteady NETwork model) program, developed by Dr. Robert Barkau (Barkau 1992) and modified by HEC. The unsteady flow simulation is actually a three-step process. First a program called RDSS (Read DSS data) runs. This software reads data from a HEC-DSS file and then converts all of the boundary condition time series data into the user-specified computation interval. Next, the UNET program runs. This software reads the hydraulic properties tables computed by the pre-processor, as well as the boundary conditions and flow data from the interface and the RDSS program. The program then performs the unsteady flow calculations. The final step is a program called TABLE. This software takes the results from the UNET unsteady flow run and writes them to a HEC-DSS file.

The post-processor is used to compute detailed hydraulic information for a set of user-specified time lines during the unsteady flow simulation period. In general, the unsteady flow computations only compute stage and flow at all of the computation nodes, as well as stage and flow hydrographs at user-specified locations. If the post-processor is not run, then the user will only be able to view the stage and flow hydrographs and no other output from HEC-RAS. By running the post-processor, the user will have all of the available plots and tables for unsteady flow that HEC-RAS normally produces for steady flow. 
Once the post-processor has finished running, the user can view output from all of the HEC-RAS plots and tables. The maximum water surface profile and user-specified instantaneous profiles can be viewed by selecting "Profiles" from the "Options" menu on each of the output windows (tables or plots). The overall maximum water surface profile will be labeled "Max W.S.," while the instantaneous profiles are labeled by the date and time. For example, a profile from January 5, 1999 at 1:00 p.m. would be labeled "05Jan1999 1300."

Viewing and printing results. Once the model has finished all of the computations, the modeler can begin viewing the results. Several output features are available under the View option from the main window. These options include: cross section plots; profile plots; rating curve plots; X-Y-Z perspective plots; hydrograph plot (if unsteady flow simulation was performed); tabular output at specific locations (Detailed Output Tables); tabular output for many locations (Profile Summary Tables); and the summary of errors, warnings, and notes.

Figure 7 is an example of a cross section plot. The user can plot any cross section by simply selecting the appropriate "River," "Reach," and "River Station" from the list boxes at the top of the plot. The user can also step through the plots by using the up and down arrow buttons. Several plotting features are available under the "Options" menu of the "Cross Section" plot. These options include: zoom in; zoom out; full plot; pan; animate; selecting which plans, profiles, and variables to plot; velocity distribution; viewing interpolated cross sections; and control over the lines, symbols, labels, scaling, and grid options.

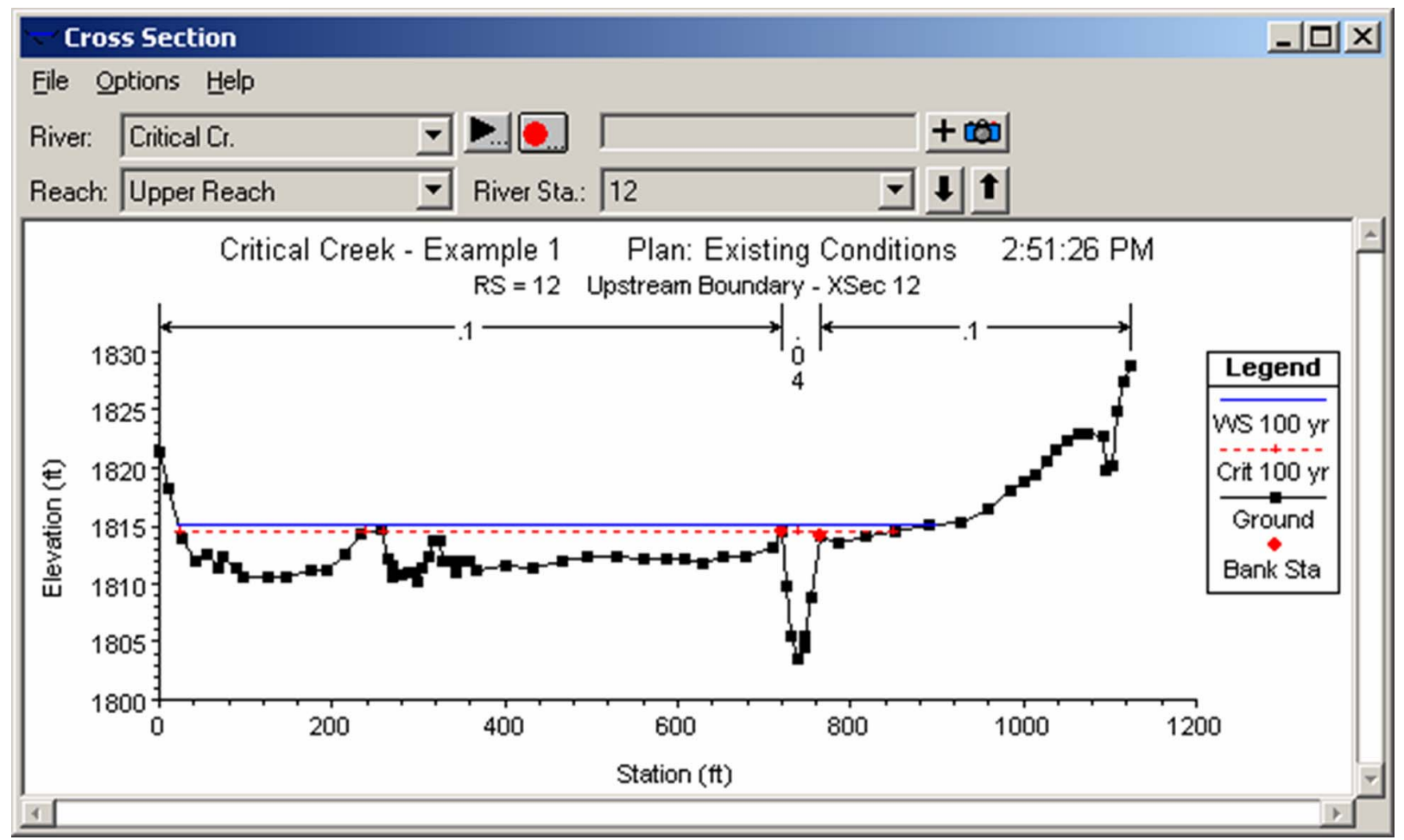

Figure 7. Cross section plot 
Hard copy outputs of the graphics can be accomplished in two different ways. Graphical plots can be sent directly from HEC-RAS to whichever printer or plotter the user has defined under the Windows Print Manager. Graphical plots can also be sent to the Windows clipboard. Once the plot is in the clipboard, it can then be pasted into other programs, such as a word processor. Both of these options are available from the "File" menu on the various plot windows.

An example of a profile plot is shown in Figure 8. All of the options available in the crosssection plot are also available in the profile plot. Additionally, the user can select which specific reaches to plot when a multiple-reach river system is being modeled.

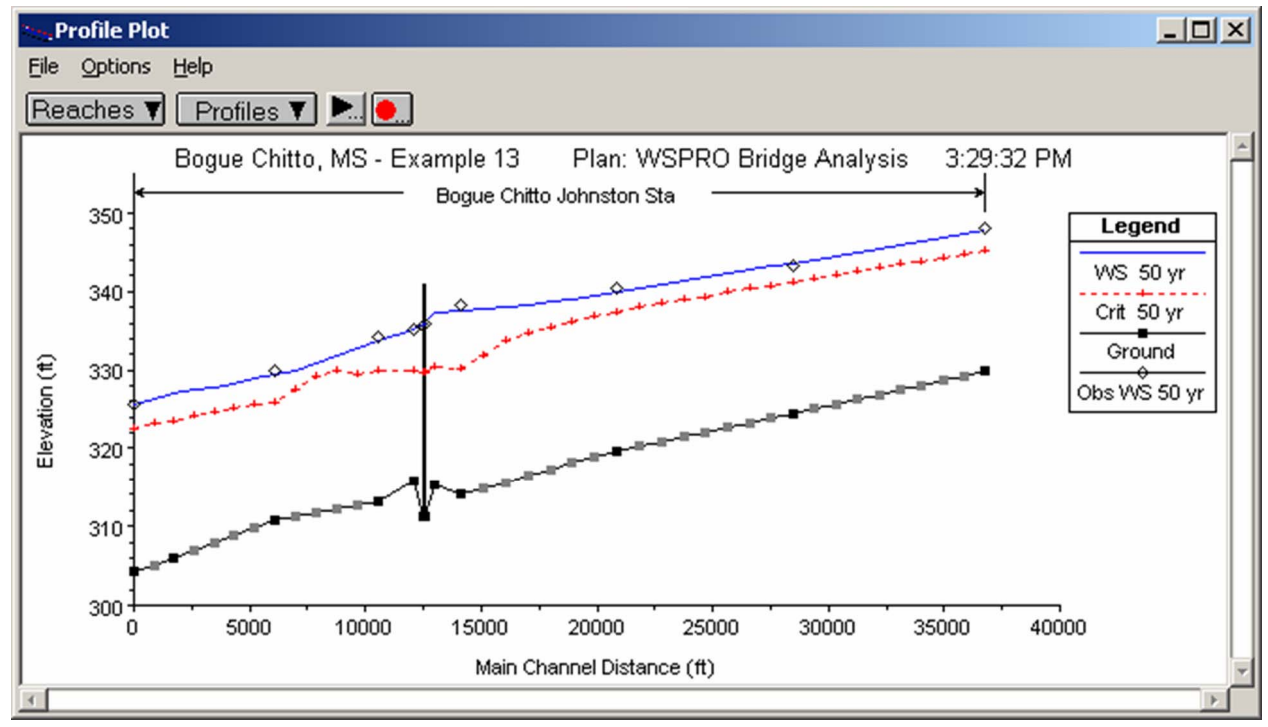

Figure 8. Profile plot

An example of an X-Y-Z perspective plot is shown in Figure 9. The user has the option of defining the starting and ending location for the extent of the plot. The plot can be rotated left or right, and up or down, in order to get different perspectives of the river reach. The computed water surface profiles can be overlaid on top of the cross-section data. The graphic can be sent to the printer or plotter directly, or the plot can be sent through the Windows Clipboard to other programs.

Tabular output is available in two different formats. The first type of tabular output provides detailed hydraulic results at a specific cross-section location (detailed output table). An example of this type of tabular output is shown in Figure 10.

The second type of tabular output shows a limited number of hydraulic variables for several cross sections and multiple profiles (profile summary tables). An example of this type of tabular output is shown in Figure 11. Several standard tables are predefined and provided to the user under the "Tables" menu from the profile output tables. Users can also define their own tables by specifying what variables they would like to have in a table. User-specified table headings can be saved and then selected later as one of the standard tables available to the project. 
X-Y-Z Perspective Plot

File Options
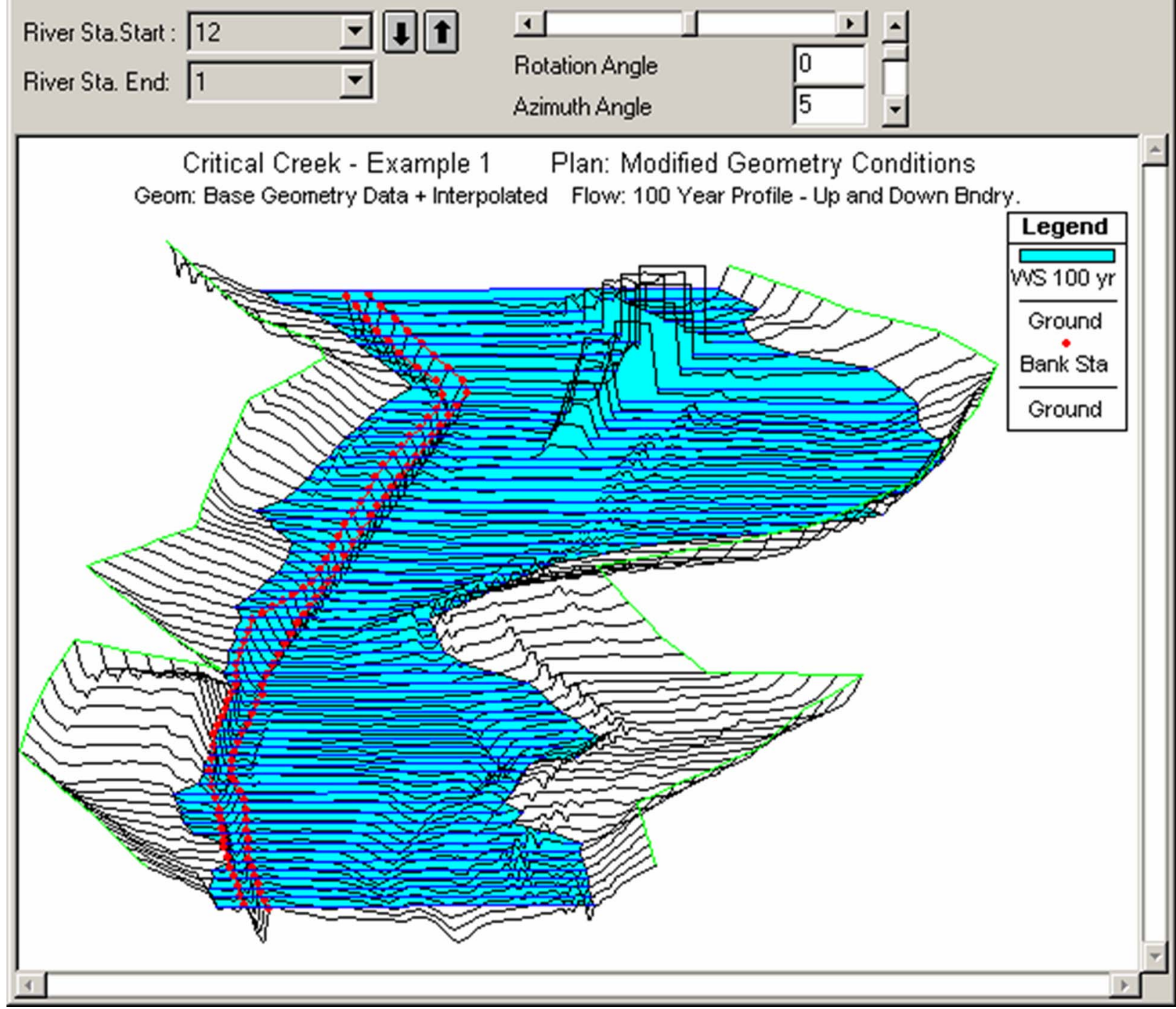

Figure 9. $X-Y-Z$ perspective plot of river reach

Tabular output can be sent directly to the printer or passed through the clipboard in the same manner as the graphical output described previously. This option is also available under the "File" menu on each of the table forms. 


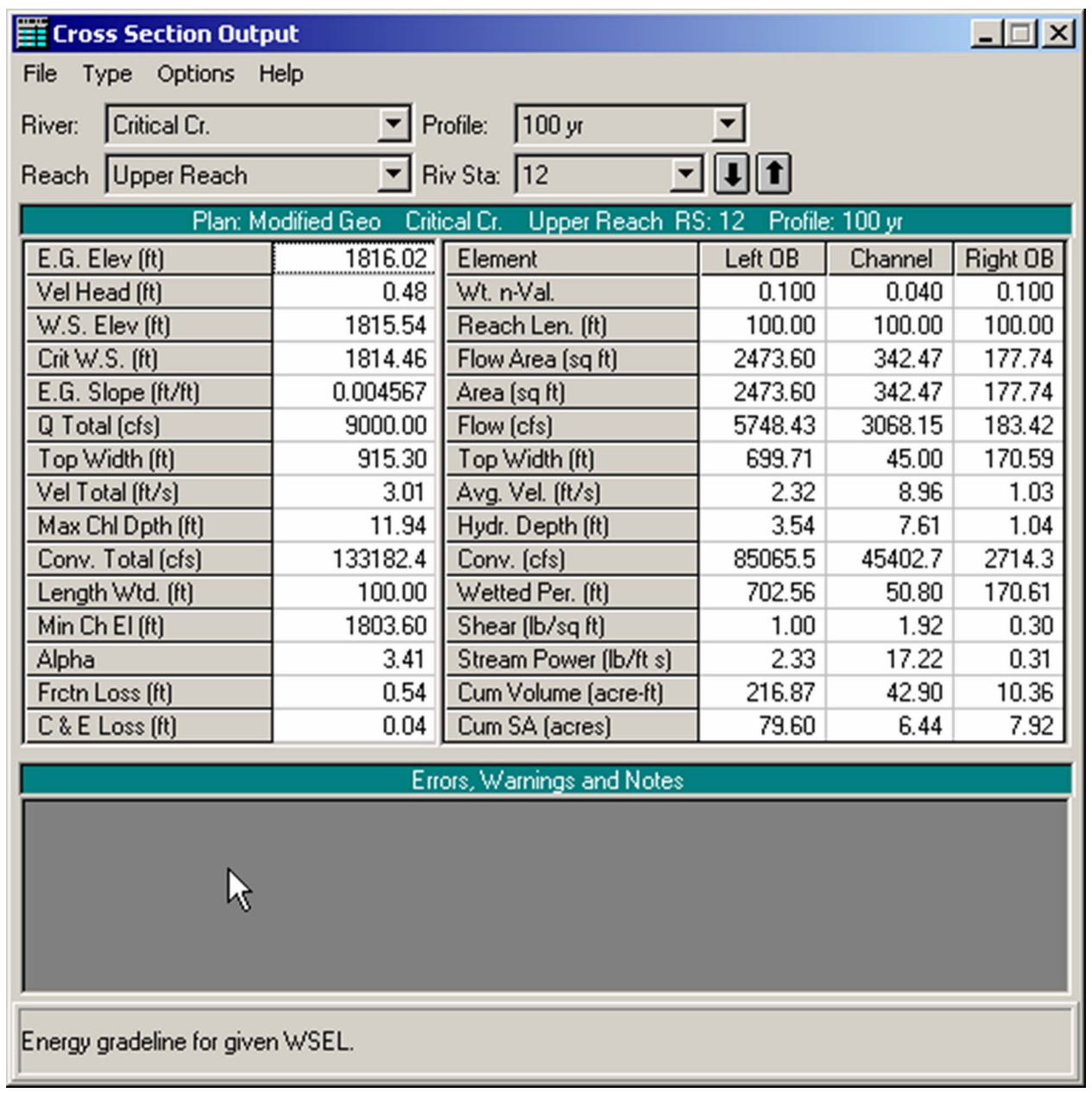

Figure 10. Tabular detailed output

\begin{tabular}{|c|c|c|c|c|c|c|c|c|c|c|c|}
\hline \multicolumn{9}{|c|}{ 邫 Profile Output Table - Standard Table 1} & \multicolumn{3}{|r|}{$-|\underline{x}| x$} \\
\hline File Options & Std. Table & $s$ Unser $T a$ & ables Loca & :ations Helf & & & & & & & \\
\hline \multicolumn{11}{|c|}{ HEC-RAS Plan: Exist Cond River: Critical Cr. Reach: Upper Reach Profile: 100 yr } & Geloadoala \\
\hline \multirow[t]{2}{*}{ Reach } & River Sta & Q Total & Min ChEI & W.S. Elev & Crit W.S. & E.G. Elev & E.G. Slope & Vel Chnl & Flow Area & Top Width & Froude \# Chl \\
\hline & & [cls] & (ft] & [it] & [ft] & (ft] & {$[\mathrm{ft} / \mathrm{t} \mathrm{t})$} & {$[\mathrm{ft} / \mathrm{s}]$} & {$[\mathrm{sq} f \mathrm{t}]$} & (ft) & \\
\hline Upper Reach & 12 & 9000.00 & 1803.60 & 1815.06 & 1814.46 & 1815.76 & 0.006851 & 10.51 & 2558.45 & 878.61 & 0.69 \\
\hline Upper Reach & 11 & 9000.00 & 1800.70 & 1810.42 & 1810.42 & 1811.87 & $\begin{array}{l}70.008552 \\
\end{array}$ & 12.03 & $\begin{array}{ll}3 & 1734.74 \\
\end{array}$ & 562.38 & 0.82 \\
\hline Upper Reach & 10 & 9000.00 & 1794.40 & 1804.46 & 1803.69 & 1804.98 & $\begin{array}{l}0.010276 \\
\end{array}$ & 10.48 & 2478.11 & 914.50 & 0.79 \\
\hline Upper Reach & 9 & 9000.00 & 1788.70 & 1799.31 & 1799.31 & 1800.16 & 6 0.008851 & 11.48 & $\begin{array}{ll} & 2719.81 \\
\end{array}$ & 1216.82 & 0.80 \\
\hline Upper Reach & 8 & 9500.00 & 1784.30 & 1793.89 & 1793.89 & 1795.08 & 0.008613 & 12.38 & 2524.66 & 1110.69 & 0.81 \\
\hline Upper Reach & 7 & 9500.00 & 1777.20 & 1789.88 & 1788.87 & 1791.00 & 0.007410 & 13.16 & 2155.56 & 526.61 & 0.76 \\
\hline Upper Reach & 6 & 9500.00 & 1774.50 & 1784.29 & 1784.29 & 1786.35 & 50.011143 & 13.38 & 1266.30 & 332.38 & 0.93 \\
\hline Upper Reach & 5 & 9500.00 & 1768.50 & 1776.81 & 1776.81 & 1778.18 & $\begin{array}{l}30.013216 \\
\end{array}$ & 13.55 & 1830.26 & 583.34 & 0.97 \\
\hline Upper Reach & 4 & 9500.00 & 1763.00 & 1773.44 & 1772.23 & 1773.88 & $\begin{array}{l}3 \\
\end{array} 0.004991$ & 9.32 & 2988.72 & 760.42 & 0.59 \\
\hline Upper Reach & 3 & 9500.00 & 1759.40 & 1767.29 & 1765.75 & 1769.34 & \begin{tabular}{|l|l|}
4 & 0.019810
\end{tabular} & 16.09 & 1610.99 & 621.76 & 1.20 \\
\hline Upper Reach & 2 & 9500.00 & 1753.60 & 1761.54 & 1760.03 & 1762.10 & 0.009413 & 10.36 & 2323.62 & 682.71 & 0.79 \\
\hline Upper Reach & 1 & 9500.00 & 1747.40 & 1756.71 & 1755.71 & 1757.21 & 0.010002 & 9.91 & 2403.99 & 728.01 & 0.79 \\
\hline
\end{tabular}

Figure 11. Profile output table 
SUPPORT SOFTWARE: HEC-GeoRAS: HEC-GeoRAS is an ArcView GIS extension specifically designed to process geospatial data for use with HEC's River Analysis System (HEC-RAS). The extension allows users with limited GIS experience to create an HEC-RAS import file containing geometric attribute data from an existing digital terrain model (DTM) and complementary data sets. Results exported from HEC-RAS may also be processed.

The current version of HEC-GeoRAS creates an import file, referred to as the RAS GIS Import File, containing river, reach, and station identifiers; cross-sectional cut lines; cross-sectional surface lines; cross-sectional bank stations; downstream reach lengths for the left overbank, main channel, and right overbank; and cross-sectional roughness coefficients. Additional geometric data defining levee alignments, ineffective flow areas, and storage areas may be written to the RAS GIS import file. Hydraulic structure data are not written to the import file at this time. Water surface profile data and velocity data exported from HEC-RAS may be processed into GIS data sets. Figure 12 illustrates how HEC-GeoRAS works together with HEC-RAS to develop a model.

Intended Application of HEC-GeoRAS. HEC-GeoRAS creates a file of geometric data for import into HEC-RAS. It also enables viewing of exported results from RAS. The import file is created from data extracted from data sets (ArcView shapefiles) and from a Digital Terrain Model (DTM). HEC-GeoRAS requires a DTM represented by a triangulated irregular network (TIN). The shapefiles and the DTM are referred to collectively as the RAS themes. Geometric data are developed from calculating the intersection of the RAS themes.

Prior to performing hydraulic computations in HEC-RAS, the geometric data must be imported and completed and flow data must be entered. Once the hydraulic computations are performed, exported water surface and velocity results from HEC-RAS may be imported back to the GIS using HEC-GeoRAS for spatial analyses such as flood inundation mapping. Figure 13 is a flood inundation plot created by HEC-GeoRAS and ArcView. GIS data are transferred between HECRAS and ArcView using a specifically formatted GIS data exchange file.

Overview of Requirements. HEC-GeoRAS 3.1 is an ArcView GIS (Environmental Systems Research Institute 1996) extension that provides the user with a set of procedures, tools, and utilities for the preparation of GIS data for import into RAS and generation of GIS data from RAS output. While the GeoRAS extension is designed for users with limited geographic information systems (GIS) experience, knowledge of ArcView GIS is advantageous. Users, however, must have experience modeling with HEC-RAS and have a thorough understanding of river hydraulics to properly create and interpret GIS data sets.

Data Requirements. HEC-GeoRAS requires a DTM in the form of a TIN. The DTM must be a continuous surface that includes the bottom of the river channel and the floodplain to be modeled. Because all cross-sectional data will be extracted from the DTM, only high-resolution DTMs should be considered for hydraulic modeling. Measurement units are relative to those in the DTM. 


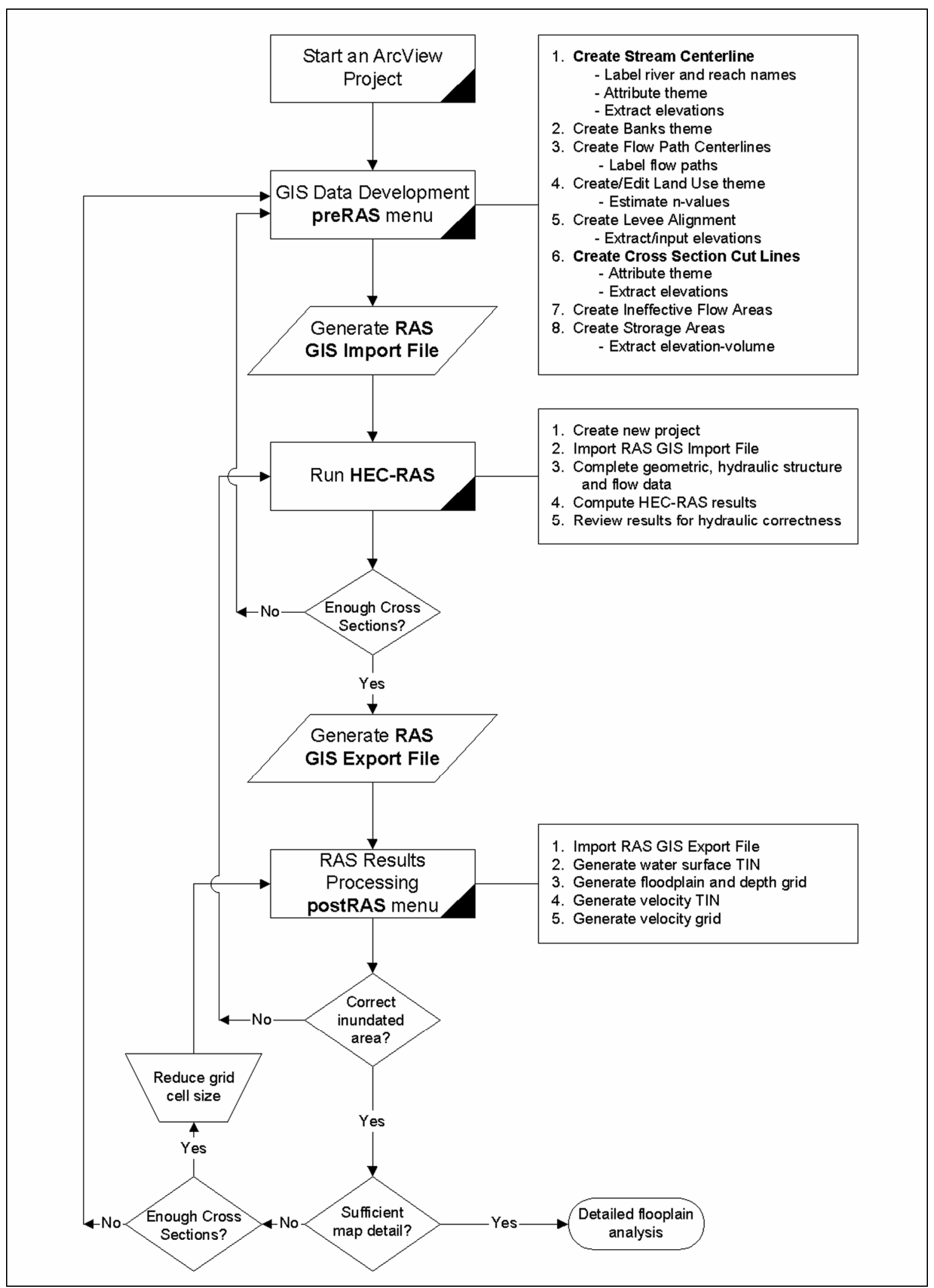

Figure 12. HEC-GeoRAS flowchart 


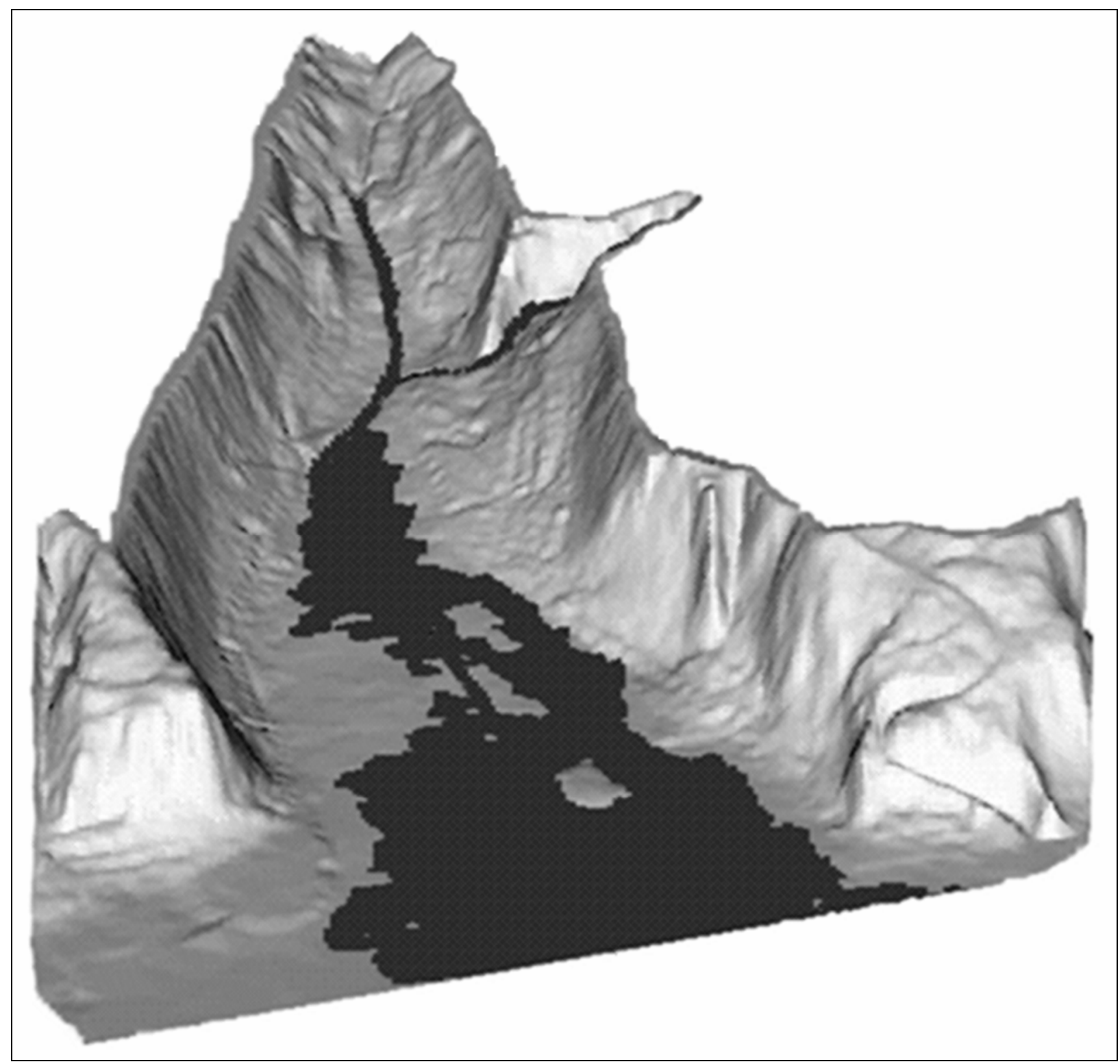

Figure 13. Flood inundation plot

MODEL DEVELOPMENT AND CALIBRATION: The primary steps involved in the development and calibration of an HEC-RAS model are outlined below:

Collection of Geographic and Hydrographic Data. This step can be as simple as determining the structural dimensions of a concrete-lined canal or as complicated as performing a full-coverage survey of the study area, including in-channel hydrosurveys. Typically, the effort is somewhere in between these two extremes. The traditional method is to survey individual cross sections at strategic locations, such as at slope changes, changes in land use, around bridges, etc. More and more common is the full coverage survey approach, in which the entire study area is surveyed and stored electronically as a digital terrain model (DTM). From this DTM, the software user can cut cross sections at any location desired. This step is usually 
the most expensive and time-consuming. Included in this first step is the collection of high water marks and/or gauge data for use in the calibration step.

Collection of Hydrologic Data. Hydrologic data are collected and analyzed to determine the boundary conditions for the HEC-RAS model. A simple steady flow, sub-critical model will only require a downstream stage and an upstream inflow as boundary conditions. More complex models may have multiple inflow and outlet boundary conditions. Typically, for a steady flow model, frequency events (i.e, 100-year, 20-year, etc.) are used as inflow boundary controls. In unsteady models, inflow hydrographs, representing a time-series of flows (real or fictitious) are used to define the inflow boundary control. Outlet boundary controls include normal depth, critical depth, rating curves, flow and stage hydrographs, or tidal cycles.

Input of Data. This step can be accomplished by manually entering in cross section and boundary condition data, or through GeoRAS. Generally speaking, this includes stationelevation data for each cross section, roughness values, ineffective flow areas, hydraulic structure (bridges, culverts, dams) geometry, and boundary conditions.

Run the Model. Running the model may take seconds or many hours, depending upon its size and complexity. Usually steady state models are completed in seconds or minutes. Unsteady flow simulations with small time-steps, and a large number of cross sections can take many hours. Depending on the results, adjustments can be made to the model input. This is necessary if errors are reported, or if the model run fails, as in the case of severe instabilities for unsteady flow models.

Calibrate the Model. Once the model has successfully run, the results must be validated by calibrating to one or more known events. Observed points can be entered into the model output for direct comparison with model results. The model input should then be adjusted to try to match the model output with the observed points. Ideally, input that has the most uncertainty (roughness values, placement of ineffective flow areas, coefficients, etc.) should be adjusted, within reason, to arrive at a fully calibrated model.

Analyze the Results. A variety of output options are available for use in HEC-RAS. Profile plots, cross-section plots, 3-D perspective plots, and tables can all be used to compile the results in useable tools for making design decisions. Most commonly, water surface elevations for various frequency events are desired for floodplain/inundation mapping, levee levels of protection determination, and navigation studies.

CASE STUDY APPLICATION-ANACOSTIA RIVER: The purpose of this study was to provide the Baltimore District of the U.S. Army Corps of Engineers (NAB) with an HEC-RAS model of the Anacostia River from the Queens Chapel Bridge on the Northwest Branch and the East-West Highway on the Northeast Branch down to the Bladensburg Marina on the main stem. The HEC-RAS model was developed from a combination of digital terrain data, existing HECRAS and HEC-2 models, CADD-generated cross sections, surveyed cross-section data, and site visits. 
The goal of the modeling effort was to evaluate the conditions on the Northwest and Northeast Branches of the Anacostia River up to the 500-year flood, including areas of levee and high ground overtopping, and to provide NAB with a useable tool for future evaluations.

Development. The HEC-RAS model was developed by importing cross-section data extracted from the ArcView GIS system. The RAS GIS Import File contained the river system schematic, cross-section station and elevation points, bank stations, reach lengths between cross sections, ineffective flow area locations, and Manning's n values. Once the terrain cross sections were imported, bathymetric data were inserted in these cross sections where available. When not available, the bathymetric data were interpolated or extrapolated, using the HEC-RAS interpolation routines and adjusted to represent actual conditions at bends, bridges, and other known features. The next step was to complete the missing cross-sectional data and modify existing data, which includes Manning's n values, contraction and expansion coefficients, ineffective flow areas, and levees. All plans were run in mixed flow regime, primarily to account for the supercritical flow experienced under most conditions in a high-velocity channel constructed for flood control.

Calibration. Because of the uncertainty involved with many of the input parameters used in hydraulic models, calibration is a necessary step to ensure confidence in the results. To calibrate this HEC-RAS model of the Anacostia River, two gauges and a physical model study were used. The two stage gauges are located on the upper ends of each of the tributary branches and are operated and maintained by the USGS.

To correctly calibrate the model to historical events, recent changes to the river had to be left out of the geometry file. More specifically, the environmental restoration efforts being undertaken to improve fish habitat were left out of the "current conditions" model. Once the model was calibrated, all of the geometry was copied to a new geometry file ("future conditions"), and the environmental restoration changes were added in. For the northwest branch, this included an increase of the $n$ value in the main channel between river station 4740 and the 38th St. Bridge from 0.035 to 0.07 to simulate a boulder garden. On the Northeast branch, a smaller fish habitat improvement was found just downstream of the Riverdale Road Bridge. This is captured in the "future conditions" model with an increase in n value from 0.03 to 0.05 at river station 17986 . Figures 14 and 15 show the calibration results at the two gauge locations, indicating the RAScomputed water surface elevations (WS), and the observed water surface elevations (OWS).

Results. The purpose of this study was to determine the approximate capacity of the levees along the northwest, northeast, and main stems of the Anacostia River. For the analysis, three RAS plans were studied: the Northwest, Northeast, and Mainstem Centering-Future Conditions. These plans are labeled future conditions, because they are set up to include further environmental enhancements, and other in-river changes. Currently, the only environmental enhancements added into these plans are the boulder garden just upstream of the 38th St. Bridge on the Northwest Branch, and the rocky fish habitat improvement just downstream of the Riverdale Road Bridge on the Northeast Branch. Others changes can be easily added in by adjusting $\mathrm{n}$ values, or physically altering the cross-section geometry. 


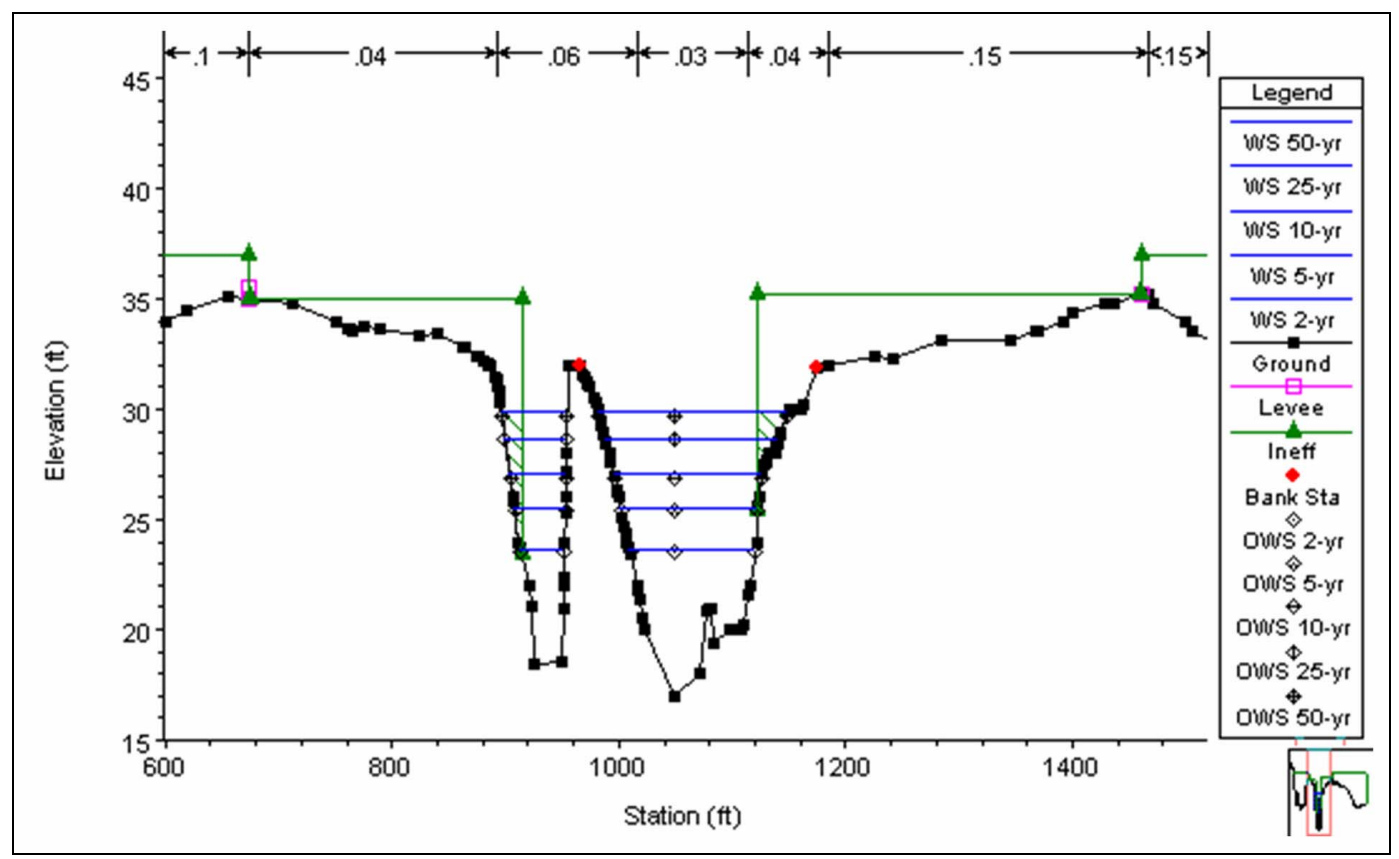

Figure 14. Calibration results at Hyattsville Gauge, Northwest Branch Centering

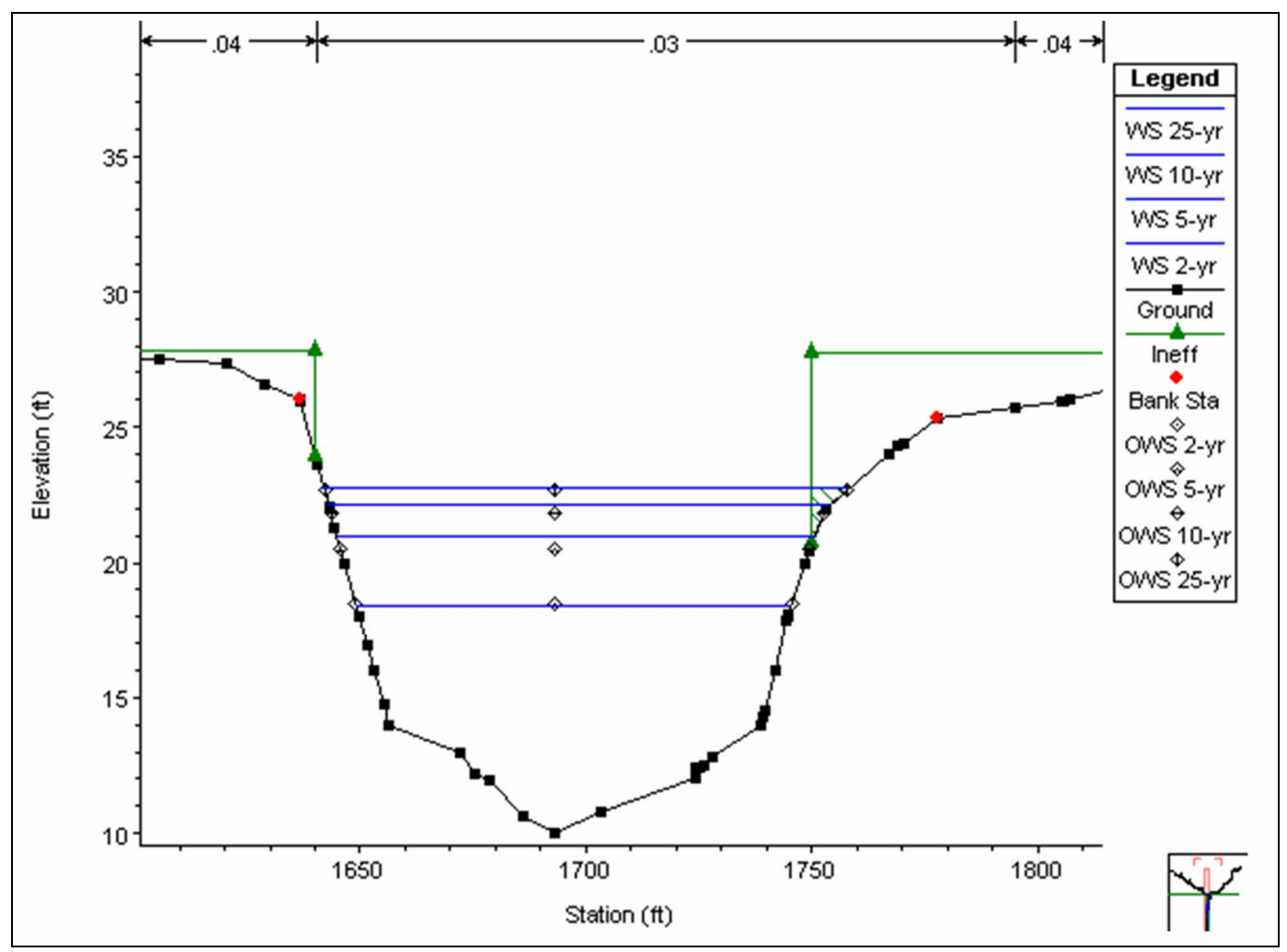

Figure 15. Calibration results at Riverdale Gauge, Northeast Branch Centering 
Based on the future conditions, it was determined that the levees contain the 100-year (1-percent chance exceedence) event, with the exception of the extreme upper limits of the Northwest Branch. While the levee system did not contain the 200 -year event everywhere, it appears that the Northeast Branch levee system can contain lower frequency flows than the Northwest Branch. The Arundel Rd. Canal appears to follow the same trend as the two main branches. The 200 -year profile briefly overtops the right levee just upstream of the 37 th St. Bridge. The 500year profile overtops the levees at all points along the canal. The main stem of the Anacostia River contains the 200-year profile within its levees at all points except at river station 6372 . The 500-year profile is still well contained between the main stem levees, with breaches occurring on the left levee at river stations 8625, 6737, and 6372.

POINTS OF CONTACT: This technical note was written by the Hydrologic Engineering Center, Hydrology and Hydraulics Technologies Center, Davis, CA, using excerpts from HEC publications and original work. For additional information, contact Mr. Gary Brunner (530-7561104,gary.w.brunner@usace.army.mil), or the Manager of the System-wide Modeling, Assessment, and Restoration Technologies (SMART) Program, Dr. Steve Ashby (601-634-2387, Steven.L.Ashby@erdc.usace.army.mil). This technical note should be cited as follows:

Goodell, C. R., and Brunner, G. W. (2004). "Watershed Analysis with the Hydrologic Engineering Center's River Analysis System (HEC-RAS)," SMART Technical Notes Collection (ERDC/TN SMART-04-2), U.S. Army Engineer Research and Development Center, Vicksburg, MS.

\section{REFERENCES}

Barkau, R. L. (1992). "UNET, One-dimensional unsteady flow through a full network of open channels," Computer Program. St. Louis, MO.

Environmental Systems Research Institute. (1996). “ArcView GIS: Using ArcView GIS,” Environmental Research Institute, Inc. Redlands, CA.

Hydrologic Engineering Center. (1997). "UNET, One-dimensional unsteady flow through a full network of open channels, User's manual, Version 4.0," U.S. Army Corps of Engineers, Davis, CA.

\section{BIBLIOGRAPHY}

Hydrologic Engineering Center. (Nov 2002). “HEC-RAS River Analysis System, User’s Manual, Version 3.1,” U.S. Army Corps of Engineers, Davis, CA.

Hydrologic Engineering Center. (Nov 2002). "HEC-RAS River Analysis System, Hydraulic Reference Manual, Version 3.1," U.S. Army Corps of Engineers, Davis, CA.

Hydrologic Engineering Center. (Oct 2002). "HEC-GeoRAS. An Extension for Support of HEC-RAS using ArcView," U.S. Army Corps of Engineers, Davis, CA.

Hydrologic Engineering Center. (May 2003). "Anacostia River Model Study. Hydraulic Analysis of the Anacostia River System using HEC-RAS,” Model Study Report. U.S. Army Corps of Engineers, Davis, CA.

NOTE: The contents of this technical note are not to be used for advertising, publication, or promotional purposes. Citation of trade names does not constitute an official endorsement or approval of the use of such products. 